\title{
OCORRÊNCIA DE LEQUES DE ARROMBAMENTO NO REGISTRO ESTRATIGRÁFICO HOLOCÊNICO DA PLANÍCIE COSTEIRA DE MARICÁ (RIO DE JANEIRO)
}

\author{
André Luiz Carvalho da Silva ${ }^{(\mathrm{a})}$, Carolina Pereira Silvestre $^{(\mathrm{b})}$
}

(a) Professor Adjunto do Departamento de Geografia da Faculdade de Formação de Professores, Universidade do Estado do Rio de Janeiro. Email: andrelcsilvageouerj@gmail.com.

(b) Doutoranda do Programa de Pós-graduação em Dinâmica dos Oceanos e da Terra, Universidade Federal Fluminense. Email: cps_silvestre@ hotmail.com.

\section{Eixo: DINÂMICA E GESTÃO DE ZONAS COSTEIRAS}

\begin{abstract}
Resumo
O presente estudo possibilitou o reconhecimento de depósitos de leques de arrombamento na estrutura interna da barreira holocênica de Maricá (RJ) e a compreensão do papel destes na evolução do litoral. A metodologia contou com levantamento topográfico para a caracterização geomorfológica e aquisição de perfis de georadar (GPR) com antena de $400 \mathrm{MHz}$. A estrutura interna da barreira é formada por um conjunto de estratos de diferentes geometrias, direções de mergulho e modos de organização relativos aos processos de sobrelavagem e formação de leques de arrombamento. Essas características permitiram compreender os mecanismos responsáveis pelo desenvolvimento da barreira, com destaque para a importante atuação do processo de sobrelavagem. Estratos inclinados na direção do continente, em torno de 1 a 4 metros de profundidade, foram interpretados como antigos depósitos de leques de arrombamento, formados por eventos meteorológicos de alta energia, e sugerem uma fase de retrogradação da barreira arenosa.
\end{abstract}

Palavras chave: Georadar, barreiras arenosas; leques de arrombamento, APA de Maricá, Brasil.

\section{Introdução}

O presente estudo objetivou o reconhecimento de depósitos de leques de arrombamento na estrutura interna da barreira holocênica de Maricá, no estado do Rio de Janeiro. Assim, como, contribuiu para a compreensão do papel destes subambientes na evolução do litoral estudado ao longo do Holoceno. A área de estudo corresponde a parte central da planície costeira de Maricá (Figura 1). Neste trecho do litoral está localizada a Área de Proteção Ambiental (APA), numa área relativamente preservada e que apresenta excelentes condições para a utilização do georadar, devido à existência de terrenos predominantemente arenosos, ausência de construções e acessibilidade. A presença de depósitos de leques de arrombamento neste trecho do litoral ocorre como resultado de uma ação intensa das grandes ondas de tempestades, que podem alcançar mais de 3 metros de altura na arrebentação (SILVA et al., 2008a), ultrapassando a barreira, removendo as dunas, a vegetação e depositando sedimentos sobre e na retaguarda desta (SILVA et al., 2008b). O processo de sobrelagavem (overwash) e a formação dos depósitos de leques de 


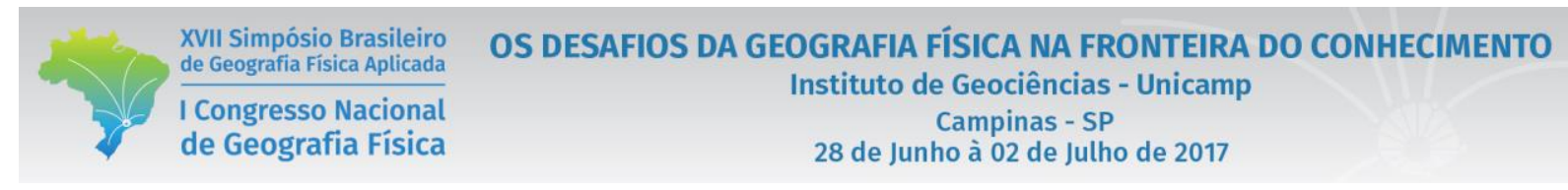

arrombamento (washover fan) modernos em Maricá são mais proeminentes em Itapuaçu (Figura 2A), e tem promovido a retrogradação da barreira holocênica. A praia atual, já se posiciona em locais anteriormente (numa escala de poucas décadas) ocupados pela vegetação de restinga (SILVA et al., 2008b). Essas feições costeiras, facilmente percebidas em superfície, também se encontram preservadas no registro sedimentar e representam um importante elemento para o entendimento da evolução da barreira no Holoceno. Esses depósitos apontam para a retrogradação da barreira em resposta a períodos marcados por eventos meteorológicos de alta energia e/ou a uma fase de elevação do nível médio do mar. Para observar o depósito de leque de arrombamente em subsuperfície são utilizados dados adquiridos com o georadar (Ground Penetrating Radar - GPR) ao longo da barreira holocênica por Silvestre (2013).

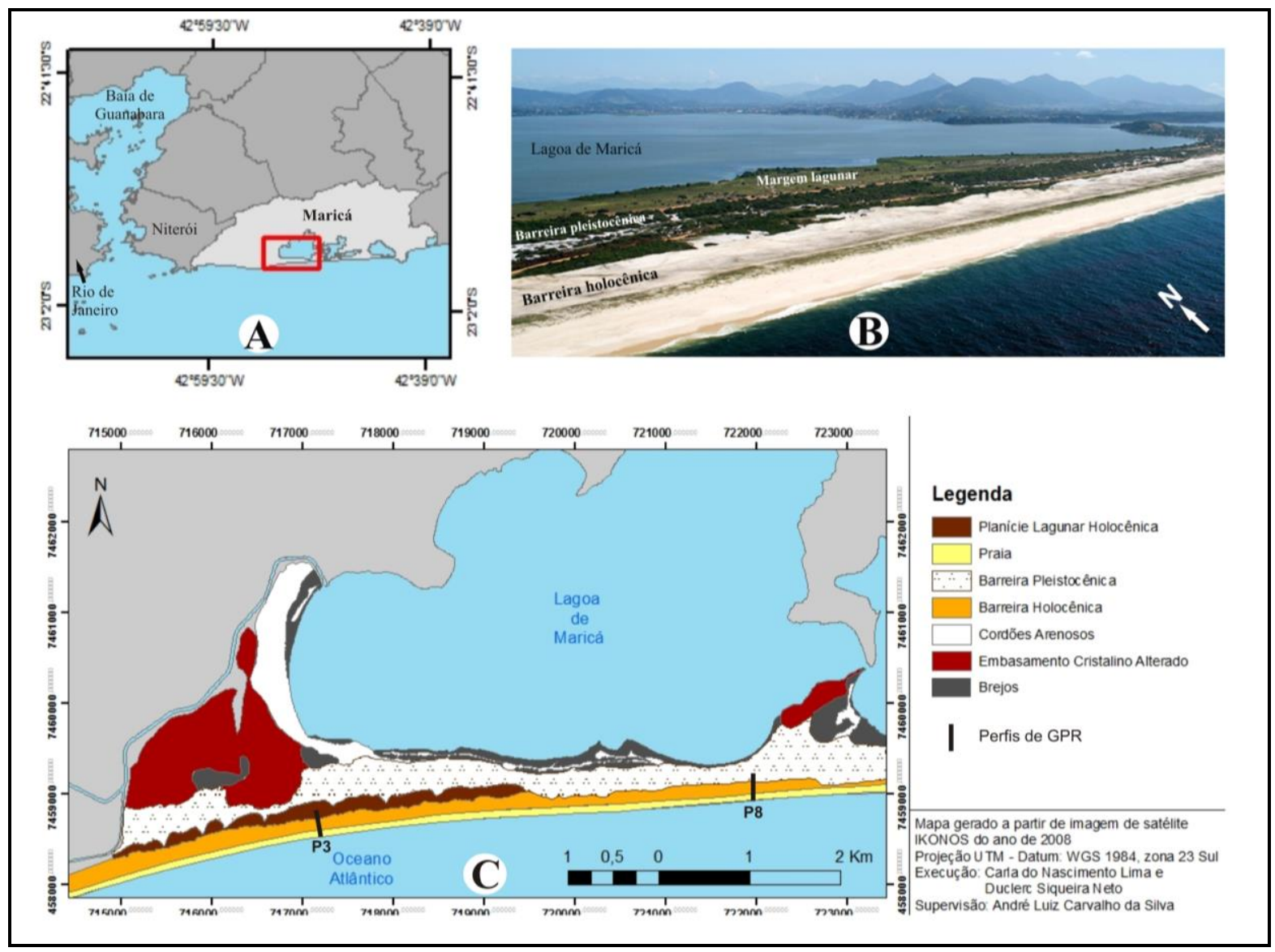

Figura 1 - Localização da área de estudo e dos perfis adquiridos com o georadar.

Os leques de arrombamento são depósitos sedimentares característicos de costas arenosas influenciadas por eventos meteorológicos de alta magnitude, comumente encontrados em barreiras arenosas (Figura 2A). Estes depósitos estão associados à ocorrência de ondas de grande energia, geradas por tempestades extremas de inverno, furacões ou tsunamis. Por isso, podem ser bons indicadores para o registro de 


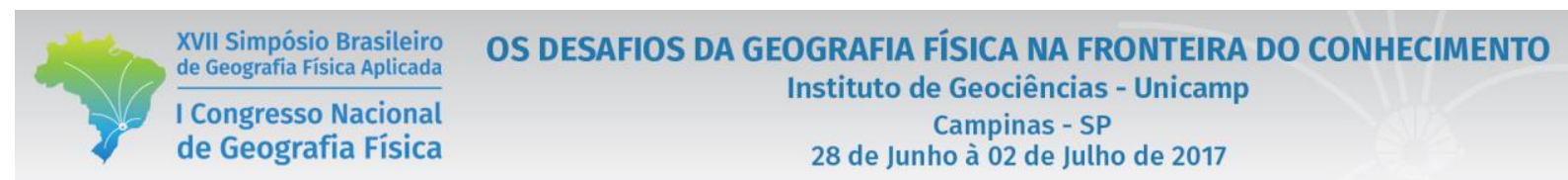

tempestades intensas na escala de tempo geológico (DONNELLY et al., 2004; BOGGS JR., 2006). A formação dos leques de arrombamento está associada ao processo de sobrelavagem que ocorre quando fortes ondas conseguem lançar água e sedimentos provenientes da praia, das dunas e da região submarina adjacente em direção ao reverso da barreira, formando um depósito em forma de leque (Figura 2B), semelhante a um lobo deltaico (MCCUBBIN, 1982). Esse processo pode alterar a morfologia de uma barreira, causando inclusive erosão de dunas (SWITZER et al., 2006).

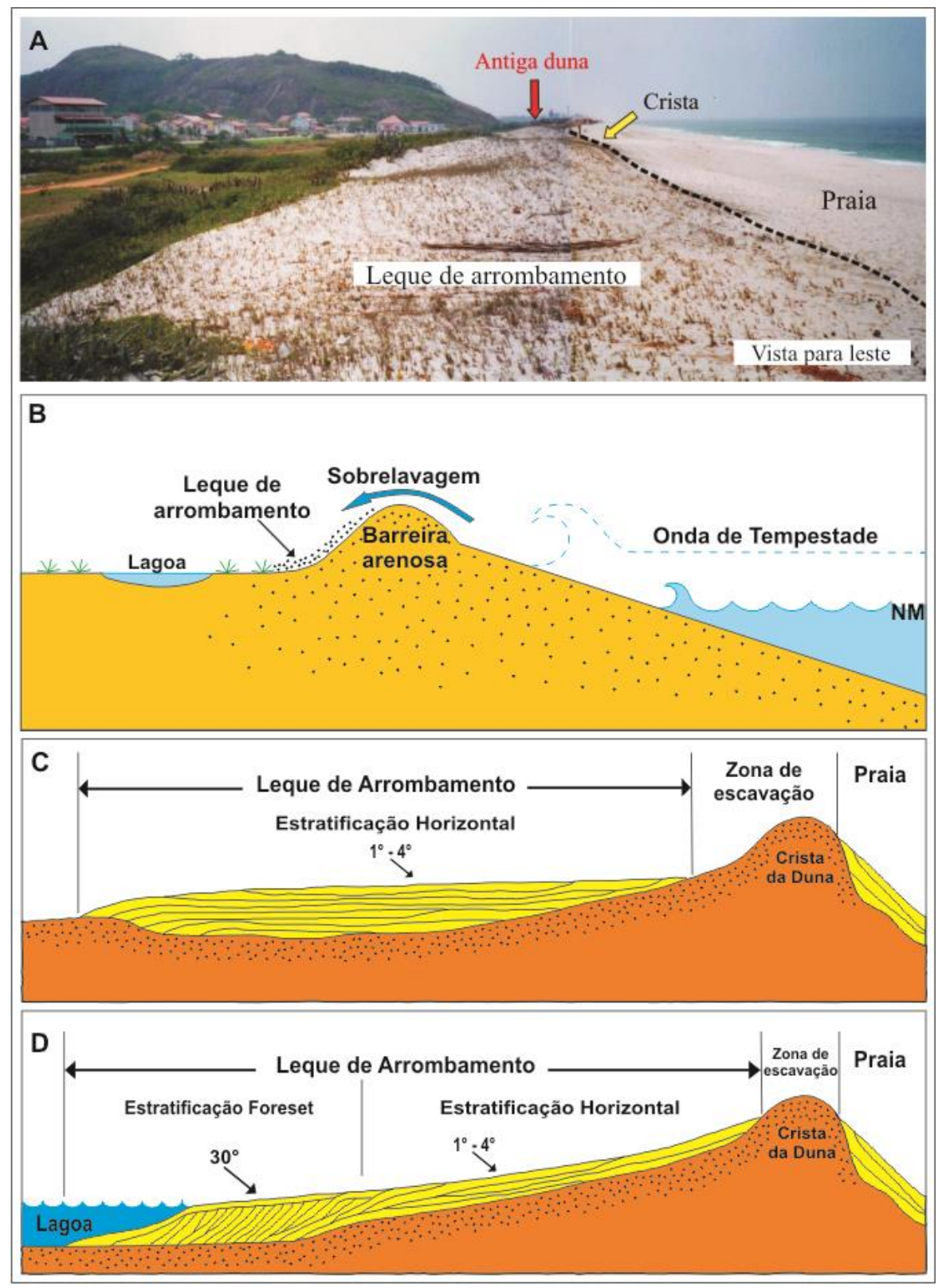

Figura 2 - (A) Leque de arrombamento em Itaipuaçú (Maricá). Imagem adaptada de Silva et al. (2008b). (B) Processo de sobrelavagem que dá origem ao leque de arrombamento. (C e D) Depósitos sedimentares e estrutura interna característicos de leques de arrombamento (Modificado de MCCUBBIN, 1982). 
Os depósitos característicos de leques de arrombamento podem apresentar estratificação planar ou planoparalela sobre a barreira (Figura 2C) e estratificação sigmoidal (topsets, foresets e bottomsets - semelhante à de um delta), caso haja uma laguna à retaguarda (Figura 2D) (MCCUBBIN, 1982). Esses depósitos podem ser encontrados tanto em costas dissipativas quanto refletivas, além de ser um mecanismo importante para a retrogradação costeira. Suas dimensões e as alterações na morfologia da barreira dependem da interação das seguintes variáveis: (1) intensidade, alcance e duração das ondas de tempestades; (2) ação construtiva ou destrutiva destas; (3) diferença entre o nível d'água do oceano e da laguna, e (4) variações batimétricas entre a porção submarina da praia e face litorânea (shoreface) (MORTON e SALLENGER, 2003). Estudos sobre a formação e evolução dos depósitos de leques de arrombamento auxiliam na compreensão da dinâmica pretérita do litoral, do comportamento das barreiras arenosas e das variações do nível do mar.

\section{2. Área de estudo}

A barreira holocênica estudada (Figura 1B e C) está localizada na planície costeira central de Maricá (RJ), a cerca de $20 \mathrm{~km}$ a leste da entrada da Baía de Guanabara, possui aproximadamente $9 \mathrm{~km}$ de extensão dentro dos limites da Área de Proteção Ambiental. É limitada ao norte pela barreira pleistocênica; a oeste pela praia de Itaipuaçú; a leste pelas praias da Barra, Guarapina e Ponta Negra; e ao sul pelo oceano Atlântico. A geomorfologia regional é caracterizada pela presença das lagoas de Maricá, Barra, Padre e Guarapina e por duas barreiras arenosas, uma de idade Pleistocênica e outra Holocênica, separadas por pequenas lagunas colmatadas (IRELAND, 1987; TURCQ et al., 1999; SILVA, 2011; SILVA et al., 2014a; SILVA et al., 2014b; SILVA et al., 2014c).

A barreira holocênica (Figura 1B e C) possui altura de cerca de 5 metros na porção oeste e 7 metros nas demais áreas, evidenciando um aumento na altura desta em direção a leste. Apresenta largura em torno de 220 metros, com relevo relativamente aplainado e com escarpas de tempestades bem definidas, demarcando o limite interno da praia (SILVA, 2011; SILVA et al., 2014c). Nesse trecho do litoral é possível observar dunas concentradas na área do reverso dessa barreira. Essas dunas possuem cerca de 12 metros de altura em relação ao nível do mar e se encontram morfologicamente alteradas devido o tráfego de veículos off road (SILVA et al., 2014c). A praia neste litoral apresenta uma variabilidade considerável na largura e na morfologia ao longo das estações do ano (GRALATO, 2013; SILVA et al., 2014c) e é conhecida pela incidência direta de ondas de tempestades, associadas à passagem da massa de ar polar proveniente do sul do continente (SILVA, 2006; SILVA et al. 2008a). A amplitude da maré neste litoral é 
inferior a 1,5 m (Diretoria de Hidrografia e Navegação), caracterizando um regime de micromaré, sendo, portanto, uma costa dominada pela ação das ondas.

\section{Metodologia}

Foram adquiridos diversos perfis topográficos e de georadar sobre a barreira holocênica por Silvestre (2013). Entretanto, para este trabalho foram selecionados os perfis 3 e 8 (Figura 1C), pois possibilitam a melhor visualização dos estratos em subsuperfície dos leques de arrombamento. Os locais para a realização dos perfis foram selecionados em função do baixo nível de urbanização e a grande extensão de área preservada (APA); viabilidade de detalhamento da área de estudo; e acessibilidade.

Os perfis topográficos realizados sobre a barreira holocênica perpendicularmente a linha dágua foram importantes para a caracterização geomorfológica da mesma e para a integração dos dados de topografia aos dados de georadar. O levantamento topográfico foi realizado com um nível topográfico acoplado a um tripé, mira e trena desde a praia até o reverso da barreira holocênica (Figura 1C). Os perfis topográficos foram geo-referenciados com GPS no sistema de navegação WGS 84. Esses dados foram processados no software Grapher 7 e integrados aos perfis de georadar.

O georadar (Figura 3) é um equipamento geofísico de alta resolução que gera imagens detalhadas e contínuas das estruturas em subsuperfície através da propagação e reflexão de ondas eletromagnéticas de alta frequência (1 a $1000 \mathrm{MHz}$ ). Essas ondas possuem melhor penetração em terrenos arenosos (alta resistividade), por isso tem sido bastante empregado em diversos ambientes costeiros. $\mathrm{O}$ equipamento é composto por duas antenas: uma transmissora, que emite um pulso eletromagnético; e outra receptora, que capta os sinais refletidos. Esse pulso é parcialmente refletido e transmitido sempre que houver uma descontinuidade eletromagnética. A profundidade e a resolução dos radargramas dependem das características sedimentares, da frequência (velocidade de penetração da onda eletromagnética) da escolha da antena e de um bom processamento (NEAL, 2004). Os perfis gerados pelo georadar permitem determinar a espessura, orientação e padrões das principais estruturas sedimentares e também inferir tendências estratigráficas, ou seja, direções de progradação, retrogradação e agradação (JOL et al., 2002).

Neste estudo foi utilizado um Georadar GSSI (Geophysical Survey Systems Incorporated) modelo SIR3000 (Figura 3A), de propriedade do CENPES-PETROBRÁS e do LAGEF-UFF. Os perfis foram obtidos com a antena de $400 \mathrm{MHz}$ blindada, deslocada manualmente desde a praia até o reverso da barreira (Figura 3B). Os parâmetros básicos utilizados para o levantamento são: 5 e $10 \mathrm{~cm}$ de espaçamento entre pontos de tiro, janela de amostragem com 200 nanoseg (cerca de 10 metros de profundidade), 1024 
XVII Simpósio Brasileiro

de Geografia Fisica Aplicada

I Congresso Nacional

de Geografia Física
OS DESAFIOS DA GEOGRAFIA FÍSICA NA FRONTEIRA DO CONHECIMENTO

Instituto de Geociências - Unicamp

Campinas - SP

28 de Junho à 02 de Julho de 2017

amostras por traço, tipo de registro em 16 Bits, método de aquisição em Survey well, antena transmissora com 100 Watts de potência radiada. Os dados adquiridos foram processados no software RADAN (Radar Data Analisy) da GSSI. Posteriormente, foram carregados e interpretados no software OpendTect 4.4.0 que permite a visualização digital dos mesmos.

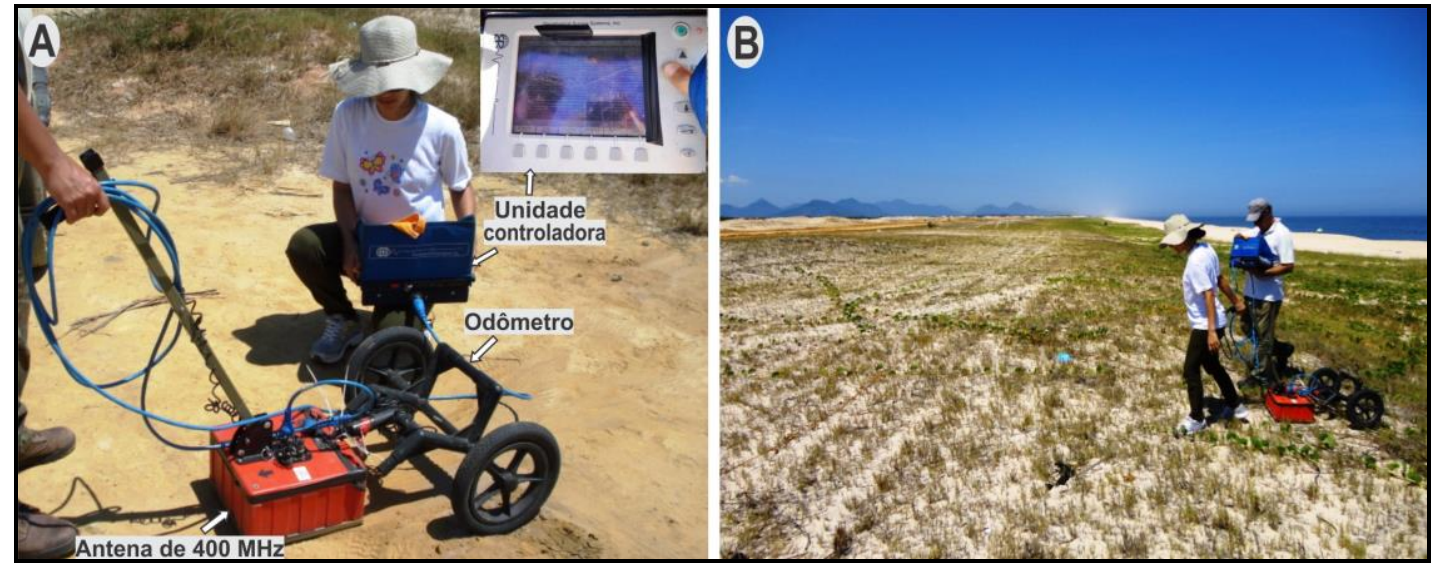

Figura 3 - (A) Georadar GSSI, modelo SIR-3000; e (B) aquisição dos perfis de GPR sobre a barreira.

\section{Resultados e discussão}

O uso do georadar permitiu a aquisição de imagens contínuas de alta resolução e a definição dos estratos em subsuperfície até a profundidade de 10 metros, assim como, o conhecimento da geometria, arquitetura sedimentar e evolução da barreira holocênica. Este método geofísico apresentou inúmeras vantagens para estudos em ambientes costeiros arenosos: facilidade de manejo no campo, baixo custo operacional quando comparado a outros métodos e a geração de dados de excelente qualidade visual e detalhamento. A escolha da antena de $400 \mathrm{MHz}$ blindada e os parâmetros empregados na aquisição e processamento dos dados foi fundamental para o êxito alcançado com a utilização desta metodologia de estudo. Os dados apresentam excelente qualidade desde o reverso da barreira até a escarpa de tempestade. Na interpretação das imagens de georadar foram empregados alguns princípios básicos de sismoestratigrafia, objetivando identificar os principais padrões de reflexão, considerando-se a forma, mergulho, intensidade, continuidade e a relação entre os refletores, baseando-se no modelo de interpretação proposto por Neal (2004).

Os perfis de georadar 3 e 8 (Figuras 4 e 5) apresentam uma camada arenosa entre cerca de 3,5 e 2 metros de profundidade, na área entre a crista e o reverso da barreira holocênica. Esse pacote sedimentar possui aproximadamente 80 metros de extensão e é limitado na base pelos refletores $\mathrm{G}$ (vermelho - Figuras 4 e 5) e H (roxo - Figuras 4), e no topo pelo refletor I (laranja - Figuras 4 e 5). A superfície representada 


\section{OS DESAFIOS DA GEOGRAFIA FÍSICA NA FRONTEIRA DO CONHECIMENTO \\ Instituto de Geociências - Unicamp \\ Campinas - SP \\ 28 de Junho à 02 de Julho de 2017}

pelos refletores $\mathrm{G}$ e $\mathrm{H}$ foi formada possivelmente pela passagem de ondas de tempestade, que promoveu a erosão parcial da parte superior da barreira (Figura 2 e 6). Já o refletor I, aparentemente, foi formado num momento em que as ondas de tempestade perderam energia, permitindo a erosão dos sedimentos possivelmente pela ação eólica.

A camada arenosa é representada por refletores e estratos internos plano paralelos na porção central da barreira e inclinados entre $11^{\circ}$ e $22^{\circ}$ para o continente na área do reverso da mesma. Em direção ao centrosul da barreira, esse pacote aparece truncado por uma escarpa de tempestade (Figuras 4 e 5), que deve ter sido causada por ondas de ressacas de menor energia. Este depósito lenticular é característico de leques de arrombamento (Figura 2) e sua estrutura vai depender da capacidade de transporte de sedimentos pelas ondas de tempestade e da morfologia da barreira. Depósitos com características semelhantes estão presentes na superfície atual da barreira e foram estudados na porção oeste do litoral de Maricá (em Itaipuaçu por SILVA et al., 2008b - Figura 2A), onde foram identificados também em subsuperfície com inclinação entre $8^{\circ}$ e $15^{\circ}$ para o continente (PEREIRA, 2009).

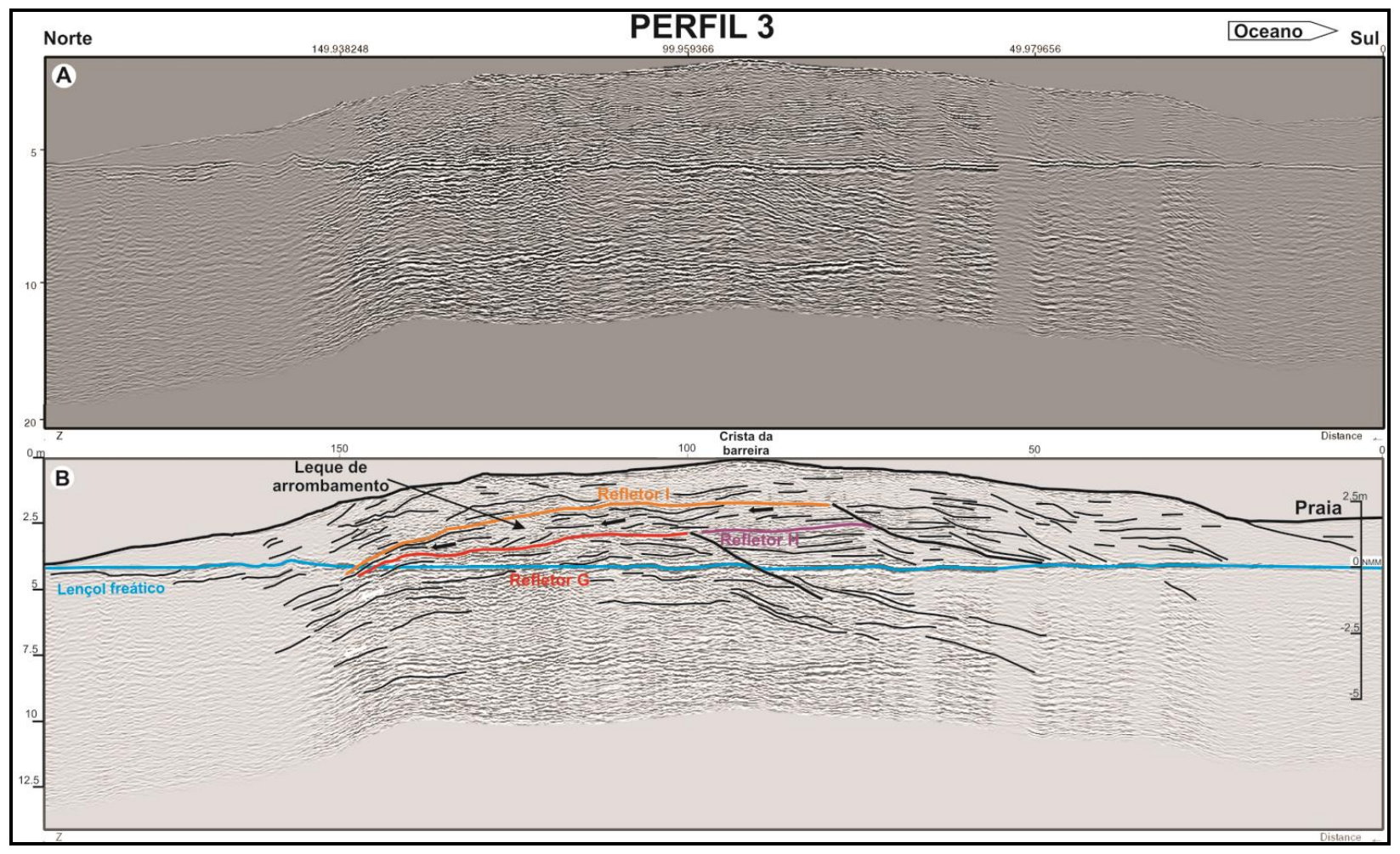

Figura 4 - (A) Perfil 3 de georadar, realizado perpendicularmente ao litoral; e (B) sua interpretação. 


\section{OS DESAFIOS DA GEOGRAFIA FÍSICA NA FRONTEIRA DO CONHECIMENTO Instituto de Geociências - Unicamp \\ Campinas - SP \\ 28 de Junho à 02 de Julho de 2017}

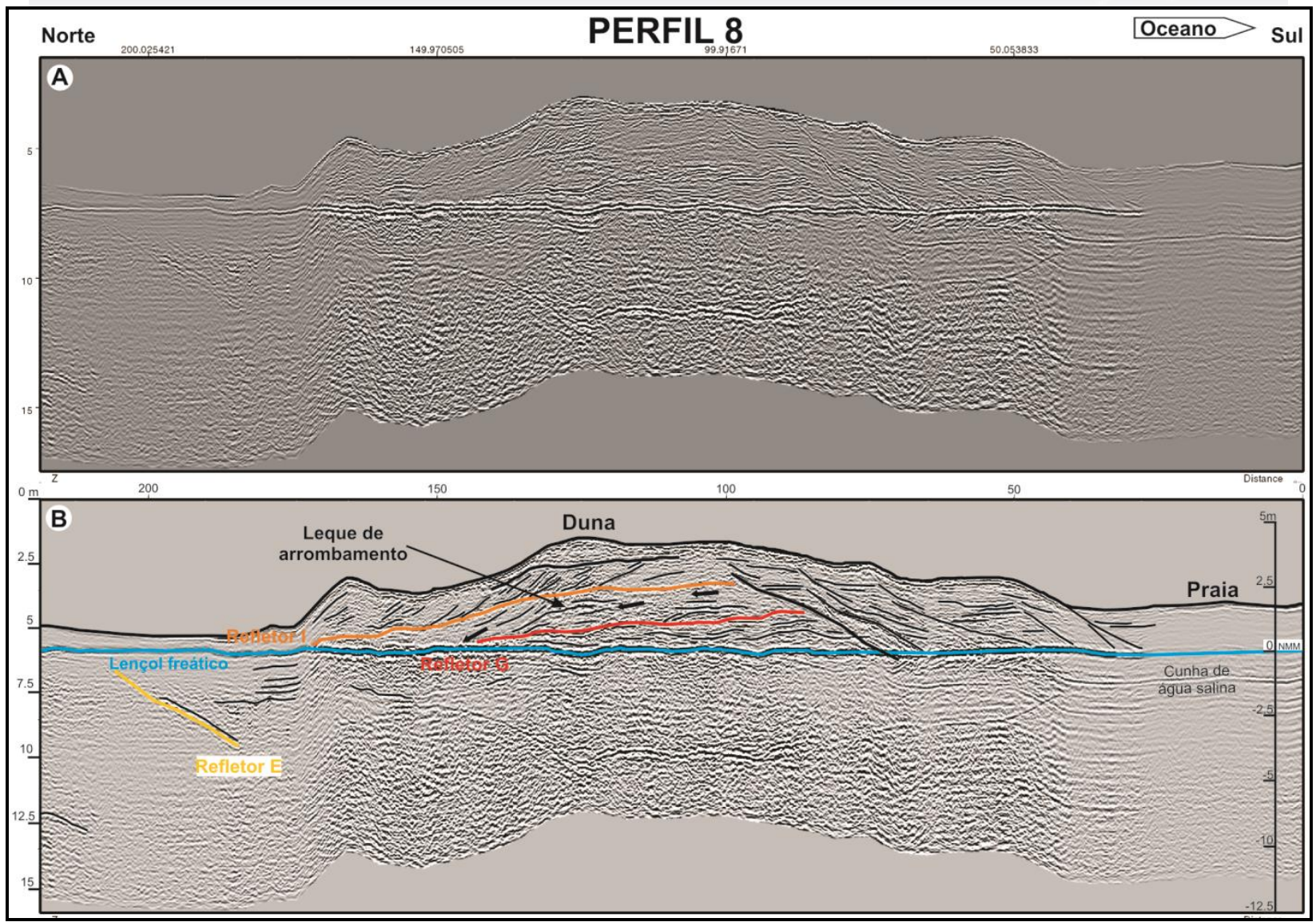

Figura 5 - (A) Perfil 8 de georadar, realizado perpendicularmente ao litoral; e (B) sua interpretação.

Esses depósitos sedimentares costeiros, formados por eventos meteorológicos de alta energia, vêm sendo estudados em diversos trechos do litoral do Brasil e do mundo (MORTON e SALLENGER, 2003, DILLENBURG et al., 2004; SWITZER et al., 2006; CALDAS et al., 2006; MATIAS et al., 2008; SEDRATI et al., 2011), e tem permitido compreender como as barreiras tendem a evoluir a partir de tal mecanismo. Estudos voltados para o entendimento da evolução dos sistemas barreira-laguna no litoral fluminense apresentam diversas evidências que apontam para uma fase de retrogradação da barreira no Holoceno. Muehe (1984) apresenta evidências de retrogradação da barreira arenosa holocênica, com base: na existência de arenitos de praia submersos paralelos aos cordões, no desaparecimento de esporões lagunares no reverso da barreira e perfis erosivos observados na parte submersa da praia. Ireland (1987), com base em dados de sondagens e datações pelo método do ${ }^{14} \mathrm{C}$, realizadas em Itaipuaçú e na Lagoa do Padre, considera que a barreira externa se formou por volta de 7.150 anos A.P. e retrogradou até ocupar a posição atual em resposta à transgressão ocorrida no Holoceno. O que também é corroborado por Turcq et al., (1999), que destaca que o sistema barreira-laguna externo teria se formado entre 7.000 e 5.000 anos 
A.P., durante a Transgressão Holocênica. Pereira et al., (2003), integrando dados de GPR e sondagem, identificou um sistema barreira-laguna pretérito associado a uma série de canais de maré que alimentavam a laguna localizada na retaguarda da barreira externa, atualmente colmatada. Sedimento turfoso encontrado na profundidade de 7,5 metros desse sistema lagunar foi datado por $\mathrm{AMS}{ }^{14} \mathrm{C}$ e revelou uma idade em torno de 6000 anos A.P. Datação de conchas provenientes do arenito de praia em Itaipuaçú, realizada por Silva (2011) e Silva et al. (2014a), forneceu uma idade de 8.560 cal. anos AP. A idade do arenito de praia permite identificar os eventos ocorridos no Holoceno, que começa com a formação de um novo sistema barreira-laguna em uma fase de nível do mar mais baixo que o atual. A transgressão holocênica ocorrida até por volta de 5.000 anos A.P. foi responsável pela retrogradação da barreira arenosa, que se encontra localizada sobre a paleolaguna com idade de 6.000 anos (datada por Pereira et al., 2003). Silvestre (2013) e Silvestre et al. (2015), com base em dados de georadar e sondagem geológica, apresentam um modelo de evolução da barreira holocênica em detalhe e indicam uma fase de retrogradação da mesma marcada por um conjunto de estratos inclinados para o continente (Figura 6). A formação dos leques de arrombamento, mapeados no registro estratigráfico holocênico em Maricá (Figuras 4 e 5), pode ter ocorrido com mais intensidade em torno de 5.000 anos AP, quando as curvas do nível do mar mostram uma elevação máxima de 3 a 5 metros para esse período (ANGULO e LESSA, 1997; MARTIN et al., 2003), portando mais susceptível a transposição de ondas e concomitante formação destes depósitos.

\section{Conclusões}

O depósito sedimentar que corresponde à barreira arenosa holocênica apresenta estratos internos indicando fases de migração do litoral de Maricá. Os dados adquiridos com o georadar sugerem uma fase de retrogradação desta barreira em resposta à elevação do nível do mar no Holoceno, facilitando o processo de sobrelavagem e a consequente formação de leques de arrombamento. Os leques de arrombamento mapeados no registro estratigráfico holocênico e àqueles observados na paisagem atual, refletem a susceptibilidade deste litoral ao fenômeno de transposição de ondas ao longo de pelo menos 5.000 anos AP.

Este e outros estudos desenvolvidos sobre a dinâmica e evolução do litoral de Maricá são essenciais para consolidar o conhecimento acerca dos ambientes costeiros, ressaltando a complexidade na formação destes sistemas. Tal conhecimento deve ser empregado num programa eficaz de gerenciamento e ordenamento do uso e ocupação da zona costeira, promovendo a conscientização ecológica e a preservação desses ambientes. 


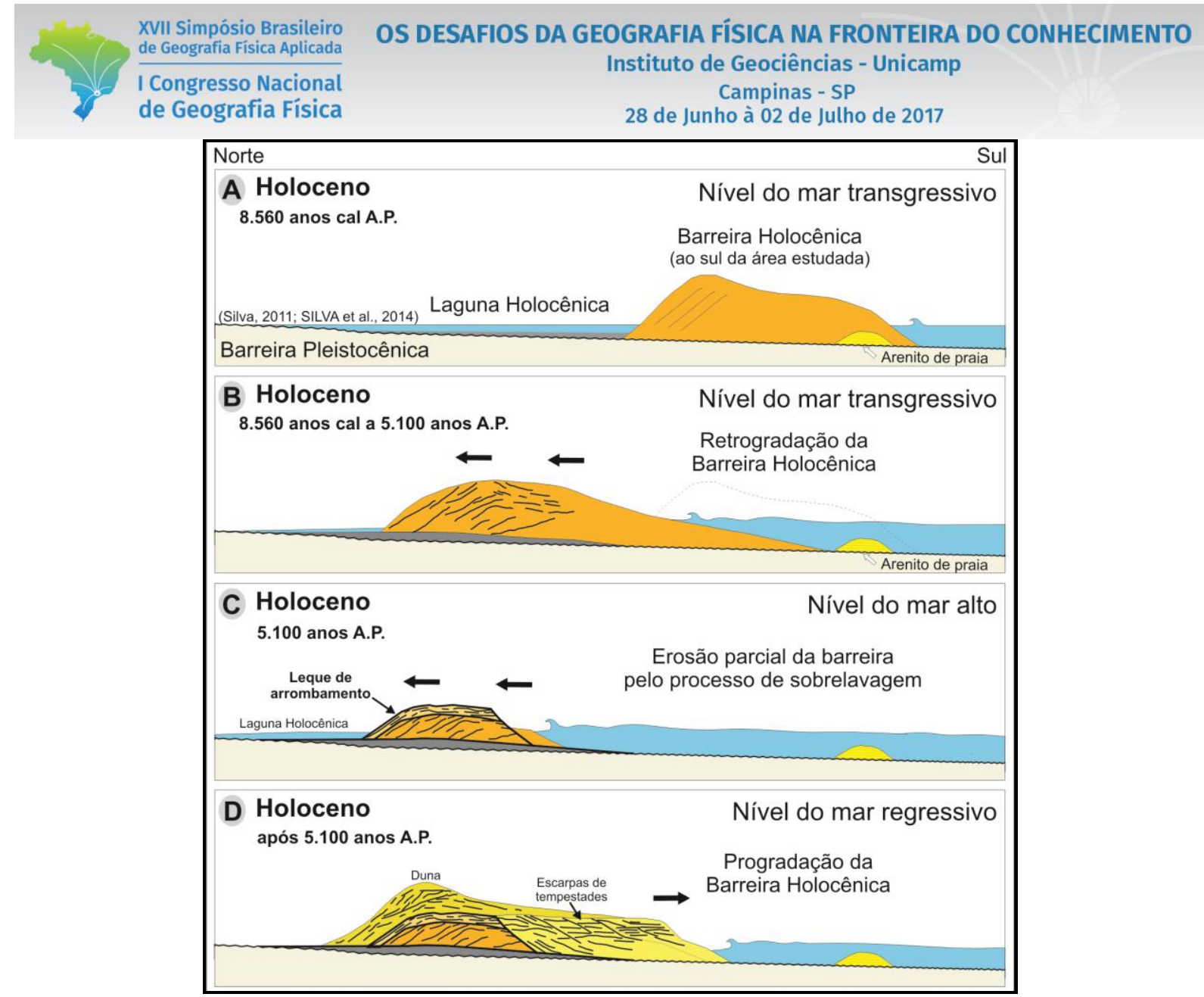

Figura 6 - (A a D) Fases evolutivas da barreira holocênica na APA de Maricá (Silvestre, 2013).

\section{Agradecimentos}

Agradecimento especial a CAPES pela bolsa de mestrado à estudante Carolina P. Silvestre. A professora Maria Augusta M. da Silva pela parceria de sempre. Ao geofísico Amilson Rodrigues pelo suporte na aquisição e processamento dos dados de georadar. Aos professores Alberto Figueiredo (LAGEMAR) e Guilherme Fernandez (LAGEF) da UFF pelos diversos equipamentos disponibilizados.

\section{REFERÊNCIAS}

ANGULO, R. J.; LESSA, G. C. The Brazilian sea-level curves: a critical review with emphasis on the curves from Paranaguá and Cananéia regions. Marine Geology, 140, p. 141-166, 1997.

BOGGS JR., S. A. M. Principles of sedimentology and stratigraphy. 4th ed. - Pearson Prentice Halt. 655p, 2006.

CALDAS, L. H. DE O.; STATTEGGER, K.; VITAL, H. Holocene sea-level history: Evidence from coastal sediments of the northern Rio Grande do Norte coast, NE Brazil. Marine Geology, 228 p. 39-53, 2006.

DILLENBURG, S. R.; TOMAZELLI, L. J.; BARBOZA, E. G. Barrier evolution and placer formation at Bujuru southern Brazil. Marine Geology, 203, p. 43-56, 2004. 


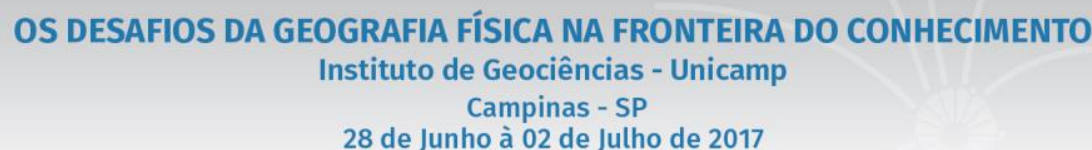

28 de Junho à 02 de Julho de 2017

DONNELLY, J. P.; BUTLER, J.; ROLL, S.; WENGREN, M.; WEBB III, T. A Backbarrier Overwash Record of Intense Storms from Brigantine, New Jersey. Marine Geology, 210, p. 107-121, 2004.

GRALATO, J. C. A. Variabilidade sazonal da praia na APA de Maricá - RJ. 2013. Monografia (Graduação em Geografia) Faculdade de Formação de Professores, Universidade do Estado do Rio de Janeiro, São Gonçalo, RJ. $71 \mathrm{p}$.

IRELAND, S. The Holocene Sedimentary History of the Coastal Lagoons of Rio de Janeiro State, Brazil. In: TOOLEY, M.; SHENNAM, I. (Eds.). Sea Level Changes. Oxford: Brazil Blackwell Ltd. p. 25-66, 1987.

JOL, H. M., LAWTON, D. C.; SMITH, D. G. Ground-penetrating radar: 2-D and 3-D subsurface imaging of a coastal barrier spit, Long Beach, WA, USA. Geomorphology, 52, p. 165-181, 2002.

MARTIN, L.; DOMINGUEZ, J. M. L.; BITTENCOURT, A. C. S. P. Fluctuating Holocene Sea Levels in Eastern and Southeastern Brazil: Evidence from Multiple Fossil and Geometric Indicators. Journal of Coastal Research. West Palm Beach, Florida. 19, 1, 101-124, 2003.

MATIAS, A.; FERREIRA, O.; VILA-CONCEJO, A.; GARCIA, T.; DIAS, J. A. Classification of washover dynamics in barrier islands. Geomorphology, 97. p. 655-674, 2008.

McCUBBIN, D. G. Barrier-Island and Strand Plain Facies. 1982. In: SCHOLLE, P. A.; SPEARING, D. Sandstone Depositional Environments. Published by The American Association of Petroleum Geologists, Tulsa, Oklahoma, 74101, U. S. A. p. $247-279$

MORTON, R. A.; SALLENGER, A. H., Jr. Morphological impacts of Extreme Storms on Sandy Beaches and Barriers. Journal of Coastal Research. West Palm Beach, Florida. 19, 3, 560-573, 2003.

MUEHE, D. C. E. H. Evidências de recuo dos cordões litorâneos em direção ao continente no litoral do Rio de Janeiro. In: LACERDA, L. D., ARAÚJO, D. S. D., CERQUEIRA, R. e TURCQ, B. Restingas: origem, estruturas e processos. Anais do Simpósio sobre Restingas Brasileiras. CEUFF - Universidade Federal Fluminense, p. 75-80, 1984.

NEAL, A. Ground-penetrating radar and its use in sedimentology: principles, problems end progress. EarthScience Reviews, 66, p. 261-330, 2004.

PEREIRA, A. J.; GAMBOA, L. A. P.; SILVA, M. A. M.; RODRIGUES, A. R.; COSTA, A. A Utilização do Ground Penetraiting Radar (GPR) em Estudos de Estratigrafia na Praia de Itaipuaçú - Maricá (RJ). Revista Brasileira de Geofísica. EDUFF, Niterói, v. 21 (2), p. 163-171, 2003.

PEREIRA, A. J. Caracterização estratigráfica da planície costeira de Itaipuaçú (Maricá) - Rio de Janeiro, durante o Quaternário. 2009. Tese (Doutorado em Geologia e Geofísica Marinha). Universidade Federal Fluminense. Niterói, RJ. p. 388.

SEDRATI, M.; CIAVOLA P.; ARMAROLI, C. 2011. Morphodynamic evolution of a microtidal barrier, the role of overwash: Bevano, Northern Adriatic Sea. Journal of Coastal Research, SI 64 (Proceedings of the 11th International Coastal Symposium), p. 696-700, 2011.

SILVA, A. L. C. Comportamento Morfológico e Sedimentológico do Litoral de Itaipuaçú (Marica) e Piratininga (Niterói), RJ, nas últimas três décadas. 2006. Dissertação (Mestrado em Geologia e Geofísica Marinha). Universidade Federal Fluminense. Niterói, RJ. p.153.

SILVA, A. L. C.; SILVA, M. A. M.; SANTOS, C. L. Comportamento Morfológico e Sedimentar da Praia de Itaipuaçú (Maricá, RJ) nas Últimas Três Décadas. Revista Brasileira de Geociências. Sociedade Brasileira de Geologia, v. 38 (1), p. 89-99, 2008a.

SILVA, A. L. C.; SILVA, M. A. M.; SANTOS, C. L.; RIBEIRO, G. B.; SANTOS, R. A.; VASCONCELOS, S. C. Retrogradação da Barreira Arenosa e Formação de Leques de Arrombamento na Praia de Itaipuaçú (Oeste de Maricá, RJ). Revista Brasileira de Geomorfologia. Ano 9, n. 2, p. 75-82. 2008 b.

SILVA, A. L. C. Arquitetura sedimentar e evolução geológica da planície costeira central de maricá (RJ) ao longo do Quaternário. 2011. Tese (Doutorado em Geologia e Geofísica Marinha). Universidade Federal Fluminense. Niterói, RJ. 185p. 


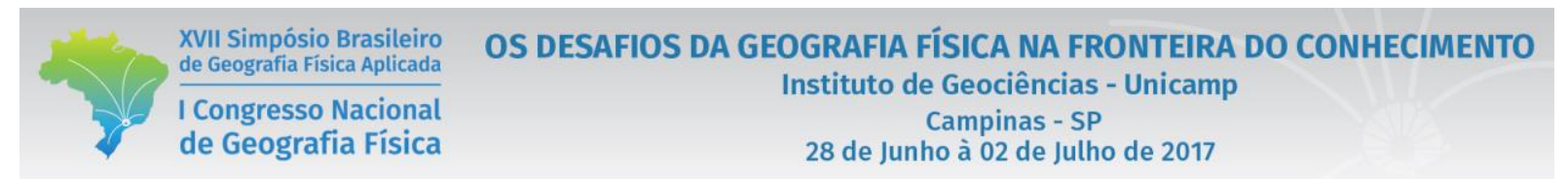

SILVA, A. L. C.; SILVA, M. A. M.; SOUZA, R. S.; PINTO, M. L. V. The role of beachrocks on the evolution of the Holocene barrier systems in Rio de Janeiro, southeastern Brazil. In: GREEN, A.N.; COOPER, J.A.G. (Eds.), Proceedings 13th International Coastal Symposium (Durban, South Africa), Journal of Coastal Research, Special Issue, n. 70, p. 170-175, 2014a.

SILVA, A. L. C.; SILVA, M. A. M.; GAMBOA, L. A. P.; RODRIGUES, A. R. Sedimentary architecture and depositional evolution of the Quaternary coastal plain of Maricá, Rio de Janeiro, Brazil. Brazilian Journal of Geology, v. 44 (2), p. 191-206, 2014b.

SILVA, A. L. C.; SILVA, M. A. M.; GRALATO, J. C. A.; SILVESTRE C. P. Caracterização geomorfológica e sedimentar da planície costeira de Maricá (Rio de Janeiro). Revista Brasileira de Geomorfologia. v. 15 (2), p. 231 249, 2014c.

SILVESTRE, C. P. Estrutura interna da barreira holocênica e seus condicionantes geológicos (Maricá - RJ). 2013. Dissertação (Mestrado em Geologia e Geofísica Marinha) Universidade Federal Fluminense. Niterói, RJ. pp. 128

SILVESTRE, C. P.; SILVA, A. L. C.; SILVA, M. A. M.; RODRIGUES, A. R. Investigation of the internal structure and evolution of the Holocene barrier of Marica (Rio de Janeiro). Revista Brasileira de Geofísica. v. 33, (3), 2015.

SWITZER, A. D.; BRISTOW, C. S.; JONES, B. G. Investigation of large-scale washover of a small barrier system on the Southeast Australian coast using ground penetrating radar. Sedimentary Geology, 183, p. 145-156, 2006.

TURCQ, B.; MARTIN, L.; FLEXOR, J. M.; SUGUIO, K.; PIERRE, C.; TASAYACO-ORTEGA, L. Origin and evolution of the Quaternary coastal plain between Guaratiba and Cabo Frio, State of Rio de Janeiro, Brazil. Environmental Geochemistry of Coastal Lagoon Systems. Série Geoquímica Ambiental - Rio de Janeiro, Brazil, 6, p. 25-46, 1999.

Site: http://www.mar.mil.br/dhn/chm/box-previsao-mare/tabuas/ (acessado em 10/10/2015). DHN - Diretoria de Hidrografia e Navegação. 